\title{
Determination of the Soil Water Characteristic Curve of Highly Compressible Materials: Case Study of Pulp and Paper By-Product
}

\begin{abstract}
A technique was developed for the determination of various points of the soil-water characteristic curve (SWCC)—including the air entry value (AEV) — of compressible materials from one single test. The testing setup, which employs the axis-translation technique, is presented and the testing methodology, explained. With the proposed methodology, it is possible to determine the volume of the sample at various stages of the desaturation process, thus making it possible to determine the degree of saturation and volumetric water content for each level of suction applied. The results of some tests performed on deinking residues (DR), a fibrous and highly compressible industrial by-product used in geoenvironmental works, are presented and discussed. It is shown that if volume changes that samples undergo during desaturation are not considered, the volumetric water content and degree of saturation of the sample is underestimated at all suction values. One important consequence is that lower hydraulic conductivities are obtained from mathematical models based on the SWCC.
\end{abstract}

KEYWORDS: suction, characteristic curve, air entry value, deinking residues, capillary barriers

\section{Introduction}

The soil water characteristic curve (SWCC) and, in particular, the air entry value of suction (AEV) are fundamental design tools in several areas of geotechnical practice where unsaturated soils are involved, such as the design of covers with capillary barrier effect (CCBE). These types of covers have been used frequently in the last decade in reclamation projects involving mine tailings or waste rock that generate acid mine drainage (Cabral et al. 1999; Aubertin et al. 1997; Woyshner and Yanful 1995; Yanful et al. 1993a,b). One of the first steps in the design of a CCBE is the determination of the SWCC of candidate materials that will create a capillary barrier.

The main aspects related to the volume change of porous materials during the determination of the SWCC are twofold: the reliability of the value of the volumetric water content $(\theta)$ at a particular value of suction, and the eventual effect of the actual value of $\theta$ when applying mathematical models to infer the unsaturated permeability function.

Most common techniques developed for the determination of the SWCC, such as pressure plates (Fredlund and Rahardjo 1993), are not able to reproduce with accuracy the SWCC of highly compressible materials, due to the important volume changes that samples undergo during testing (Proulx 1997; Planchet 2001). Such important volume changes render the determination of the volumetric water content (or the degree of saturation) during testing extremely difficult, if not inaccurate. The use of empirical formulations based

Received September 5, 2003; accepted for publication May 2, 2003; published February 9, 2004.

${ }^{1}$ Professor, Department of Civil Engineering, Université de Sherbrooke, Quebec, J1K 2R1, Canada.

${ }^{2}$ Premier Tech, Rivière-du-Loup, Quebec, Canada (Former Graduate Research Assistant).

${ }^{3}$ Associate Professor, Escola Politécnica da Universidade de São Paulo, C.P. 61548, São Paulo, SP 05424-970, Brazil.

${ }^{4}$ Professor, Department of Civil Engineering, Université de Sherbrooke, Quebec, J1K 2R1, Canada. on the granulometry of the material is also not always applicable, given the impossibility of obtaining the granulometric distribution of, for example, fibrous materials. As a consequence, there is a need to develop new methods to obtain the SWCC and AEV for highly compressible materials.

This paper presents a technique developed at the Geoenvironmental laboratory of the Université de Sherbrooke that allows for the determination of the SWCC of compressible materials. The results of tests performed on deinking residues (DR), a fibrous and highly compressible industrial by-product (Burnotte et al. 2000), are presented and discussed. The testing setup that was developed employs the axis-translation technique (Fredlund and Rahardjo 1993) to determine the volumetric water content at various stages of the desaturation process. Of particular relevance is the possibility to monitor the variation of the degree of saturation, volumetric water content, and void ratio during the tests. As a result, various points of the SWCC, including the air entry value (AEV), can be obtained from one single test. The paper also discusses some difficulties relating to sample preparation and compaction.

\section{Background}

\section{Prevention of Acid Mine Drainage (AMD) by Capillary Barriers}

AMD occurs as a result of the oxidation of sulphide-rich minerals contained in tailings and waste rock when the latter are exposed to oxygen and water. It can only be generated if the three elements (sulfide-rich minerals, water, and oxygen) are present at the same time. Prevention and control measures against AMD generation rely on preventing one of these elements from entering the system.

The capillary barrier in a cover system is formed when a layer of fine-grained material is placed over a layer of coarse-grained material (Aubertin et al. 1997). With the contrast in hydraulic properties of the two materials (SWCC, saturated and unsaturated hydraulic conductivity), the fine-grained layer is able to maintain a high degree 
of saturation, irrespective of the degree of saturation of the underlying coarse-grained layer (Nicholson et al. 1989; Barbour 1990). Since the coefficient of diffusion of oxygen through a saturated or nearly saturated layer is approximately four orders of magnitude lower than in air (Cabral et al. 2000; Yanful 1993), oxygen fluxes are drastically reduced, thus preventing or reducing the generation of AMD (Cabral et al. 2000; Yanful 1993). The basic hydraulic principles of capillary barriers are well explained by Nicholson et al. (1989), Barbour (1990), and Aubertin et al. (1997) among others.

\section{The SWCC and its Determination}

The SWCC defines a constitutive relationship between water content (volumetric or gravimetric), degree of saturation, and suction. It provides a conceptual framework in which the behavior of unsaturated soils can be understood (Barbour 1998). Figure 1 presents a schematic representation of the change in void ratio, degree of saturation, volumetric and gravimetric water contents in relation to changes in suction, for an assumed value of 2.6 for the specific gravity of the solids. In this example, the material remains saturated up to a suction of $10 \mathrm{kPa}$ (Fig. 1). This suction value is called the air entry value $(\mathrm{AEV})$ of the material, since it is at that value of suction that the material starts to desaturate. For a complete review about
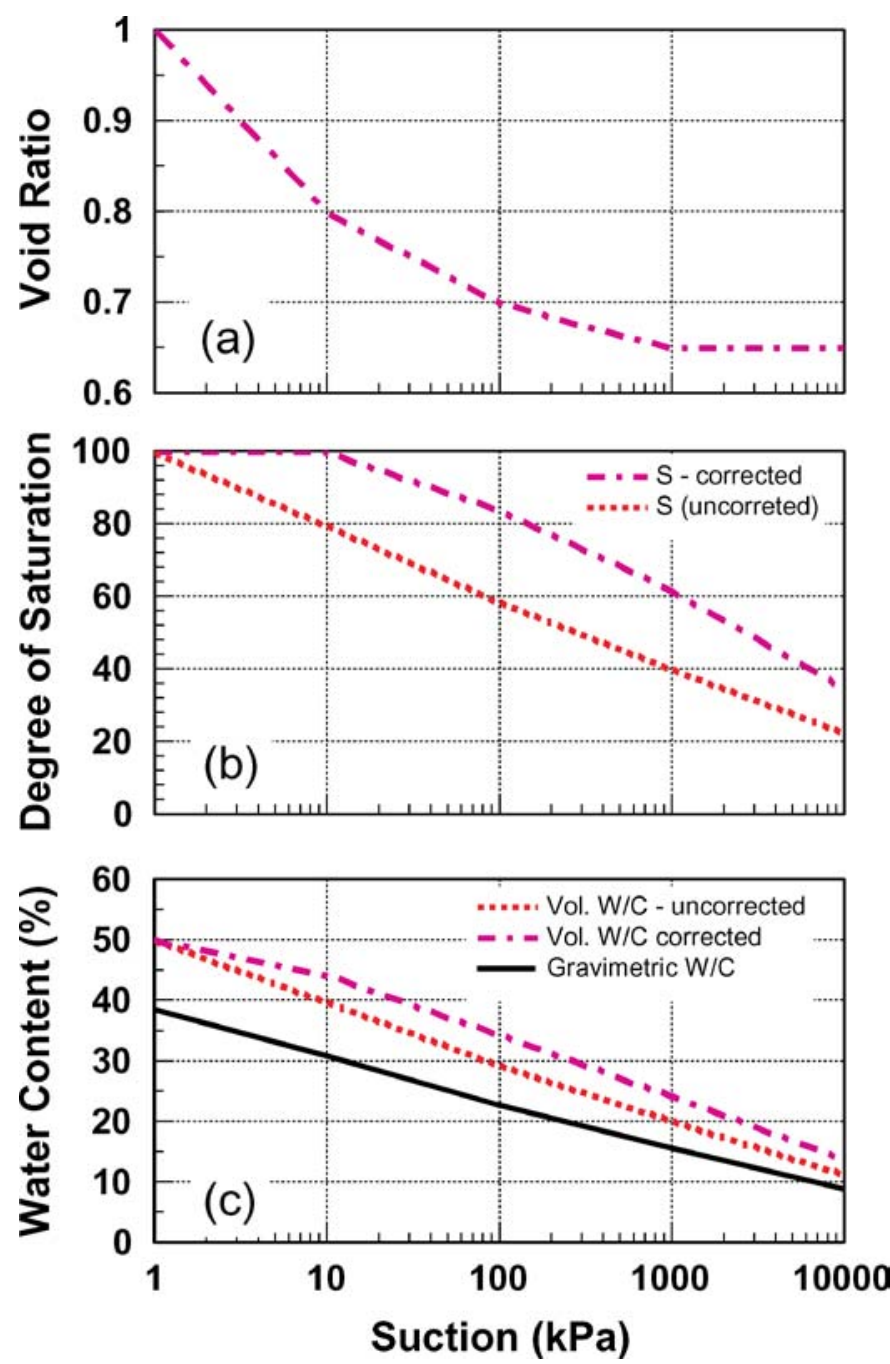

FIG. 1-Schematic representation of the suction relations for a compressible material.
TABLE 1-Methods to determine the SWCC.

\begin{tabular}{lcc}
\hline \multicolumn{1}{c}{ Method } & Suction range (kPa) & Reference \\
\hline & (a) Suction control methods \\
\hline $\begin{array}{l}\text { Tensiometric plaques } \\
\text { Pressure plate }\end{array}$ & 0 to $10^{2}$ & $\begin{array}{l}\text { Croney (1952) } \\
\text { Richards and Fireman } \\
(1943)\end{array}$ \\
Centrifugation & 0 to 2500 & $\begin{array}{c}\text { Croney and Coleman } \\
(1954)\end{array}$ \\
Vacuum Dessicator & $10^{2}$ to 3162.3 & $\begin{array}{c}\text { Fredlund and Hahardjo } \\
(1993)\end{array}$
\end{tabular}

(b) Suction measurement methods

\begin{tabular}{lcc}
\hline Psychrometry & $10^{2}$ to $8^{*} 10^{4}$ & Verbrugge (1974) \\
Tensiometer & 0 to 80 & Black and Corey (1957) \\
Filter paper & 1 to $10^{4}$ & Fawcett and Collis-George \\
& & $(1967)$
\end{tabular}

the SWCC, the reader is referred to Fredlund and Rahardjo (1993), Marinho (1994), and Barbour (1998).

There is no simple, standard, or universally accepted procedure to determine the SWCC, nor one that allows obtaining with precision the volumetric water content for the wide range of possible suction levels in a soil. The SWCC can be obtained using basically two water content paths: the drainage (or drying) and the wetting paths. Usually, the drying path is used for obtaining the SWCC due to its simplicity. In the laboratory, the determination of each point of the SWCC is based on the measurement of the capillary pressure (or matric suction) inside a sample and the amount of water retained when equilibrium is reached at each stage of suction. Increasing the suction leads to a reduction in water content, whereas a reduction in suction results in absorption of water by the sample. The equilibrium between the sample and the measuring system is also necessary, and depends on the technique used to measure the suction.

The determination of the SWCC implies the control of water content and measurement of suction, or the control of suction and measurement of water content. Some of the methods used to impose suction to the sample are listed in Table $1 a$. The methods used to measure suction after a controlled reduction in water content are listed in Table $1 b$. It should be pointed out that, in both cases, the sample has to be at equilibrium, i.e., there must be no flow inside the sample for all practical purposes.

Compressible porous material can remain saturated even if pore water is expelled out of it. This behavior is due to the fact that the volume change of the sample is equal to the volume of water lost. If the volume change is not taken into account, the volumetric water content is underestimated (see Fig. $1 c$ and Fig. 6). As a consequence, the value of the hydraulic conductivity $(k)$ obtained by mathematical models based on the SWCC may be significantly underestimated at low levels of suction. At values of suctions less than the air entry value, $k$ equals $k_{\text {sat }}$, which is the highest possible value.

Indirect methods to obtain the SWCC are also available. These methods are based on texture (granulometry). A wide body of literature is available about the use of texture to determine the SWCC (e.g., Brooks and Corey 1964; Fredlund et al. 1997).

\section{Materials and Methods}

\section{Deinking Residues}

Pulp and paper residues, such as deinking residues, were once considered as wastes and landfilled at great costs. In the last decade, 
they have been employed with success as the fine-grained material layer in a CCBE (Cabral et al. 1999), and as part of the cover system in several MSW landfills in the U.S. (Kraus et al. 1997; Moo-Young and Zimmie 1996), Canada (Burnotte et al. 2000), and South Africa (Brown et al. 1998).

An evaluation of the physicochemical composition of the deinking residues used in this study showed that calcite represents between 17 and $22 \%$ of the dry weight of the material. Its presence was verified by X-ray diffraction using a Rigaku Geigerflex, and quantified by X-ray fluorescence using a Philips PW 14110. Thermogravimetry-Differential Thermal Analysis (TG/DTA) reconfirmed the calcite content. The organic matter consists mainly of cellulose. Samples of fresh residues were analyzed in the scanning electron microscope. The images show that the inorganic fraction forms mainly crumbs between the fibers (Cabral et al. 2000).

Compaction curves were obtained for several deinking residues using the ASTM D 698 ("Standard Proctor") procedure, as well as varying field compaction procedures. Cabral et al. (2000) presents Standard Proctor compaction curves for several fresh deinking residues obtained in the laboratory, whereas Burnotte et al. (2000) presents the curves obtained from composite samples taken from barriers already compacted in the field. The maximum dry unit weight varies from 5.0 to $5.6 \mathrm{kN} / \mathrm{m}^{3}$, whereas the optimum water content varies from 60 to $90 \%$.

\section{Testing Equipment}

Figure 2, adapted from Planchet (2001), presents a scheme of the testing apparatus developed at the Soil Mechanics and Geoen- vironmental Laboratory of the Université de Sherbrooke to test compressible materials. The system consists of an 11.54-cm-high, 15.85-cm-diameter cell made of Plexiglas (based on a "null type pressure cell"), a pressure regulator (controls air pressure applied to the top of the sample and to the burette CELL), and several valves that can be opened or closed as needed. As shown in the diagram of Fig. 3, the sample is placed in a pedestal on top of a porous stone (described later). The top cap, through which air is applied to the sample, is slotted at its bottom in order to allow for a better distribution of the air pressure across the upper surface of the sample. The sample is isolated from the water of the cell by two flexible membranes.

Pressure is applied to the top of the sample $\left(P_{\text {in }}\right)$, while water is collected from the bottom to the burette OUT, which is at atmospheric pressure $\left(P_{\text {out }}=P_{\mathrm{atm}}\right)$. The water level in the burette OUT is kept as close as possible to the elevation of the middle of the sample. This is done in order to ensure that the only hydraulic gradient applied is the one associated with the application of air at the top of the sample. As shown in the diagrams of Figs. 2 and 3, the cell pressure $\left(P_{\text {cell }}\right)$ is always $20 \mathrm{kPa}$ higher than $P_{\text {in }}$. This pressure corresponds approximately to the stress applied to the deinking residues (DR) by the protective layer in actual field conditions. It not only ensures good contact between the membrane and the sample (thus avoiding air leakage between the two), but also prevents the sample from being fractured when air is applied from the top, which would lead to an erroneous evaluation of the AEV. The sample is compacted directly over the $1.01-\mathrm{cm}$-thick, 5.39 -cm-diameter porous stone that is previously cleaned in an ultrasound bath and saturated by means of vaccum pumping. In order to enhance saturation, the porous stone is placed in a bowl containing only deaerated water,

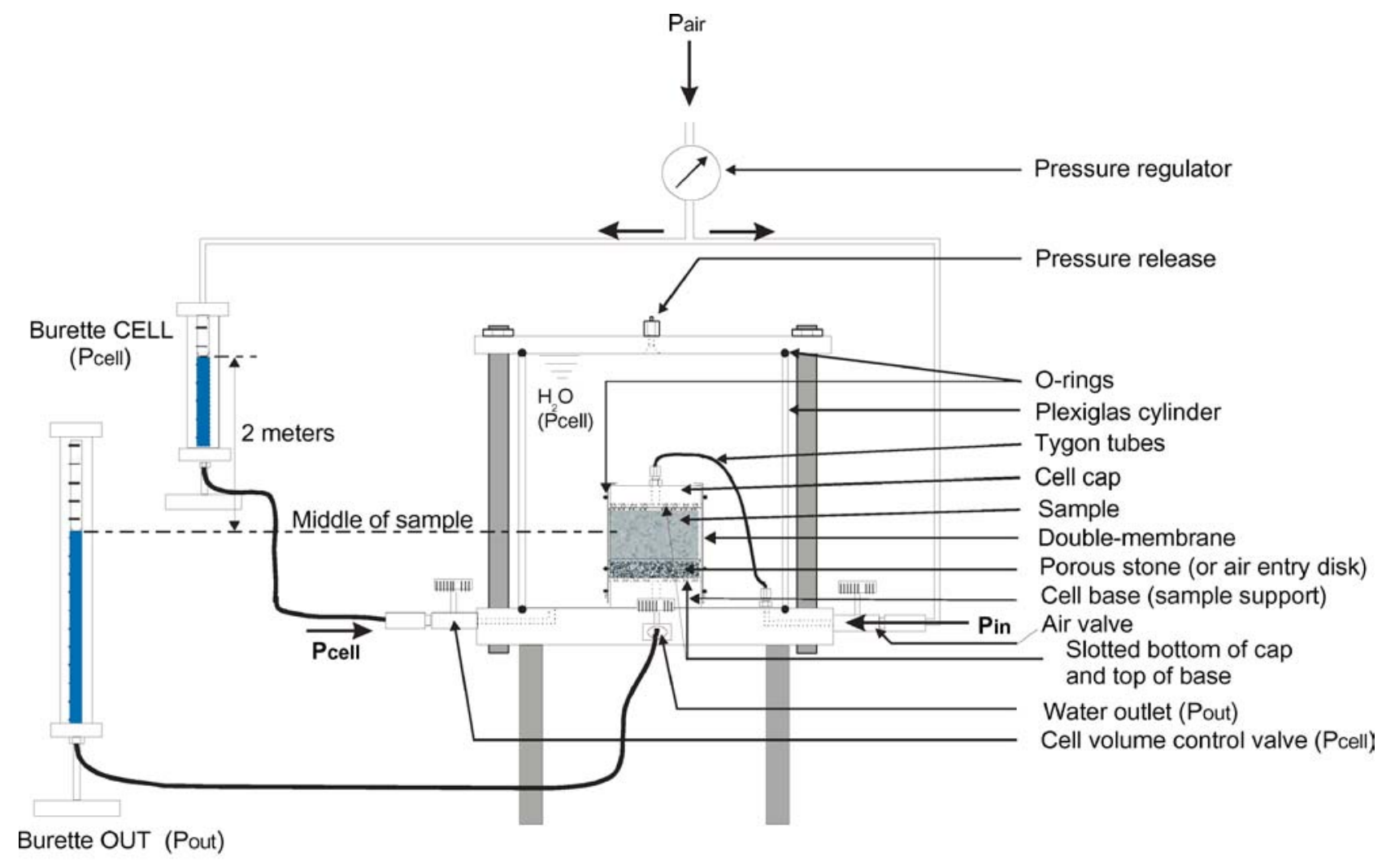

Note: The notation P stands for pressure

Not to scale

FIG. 2-Scheme of the UdeS cell. 


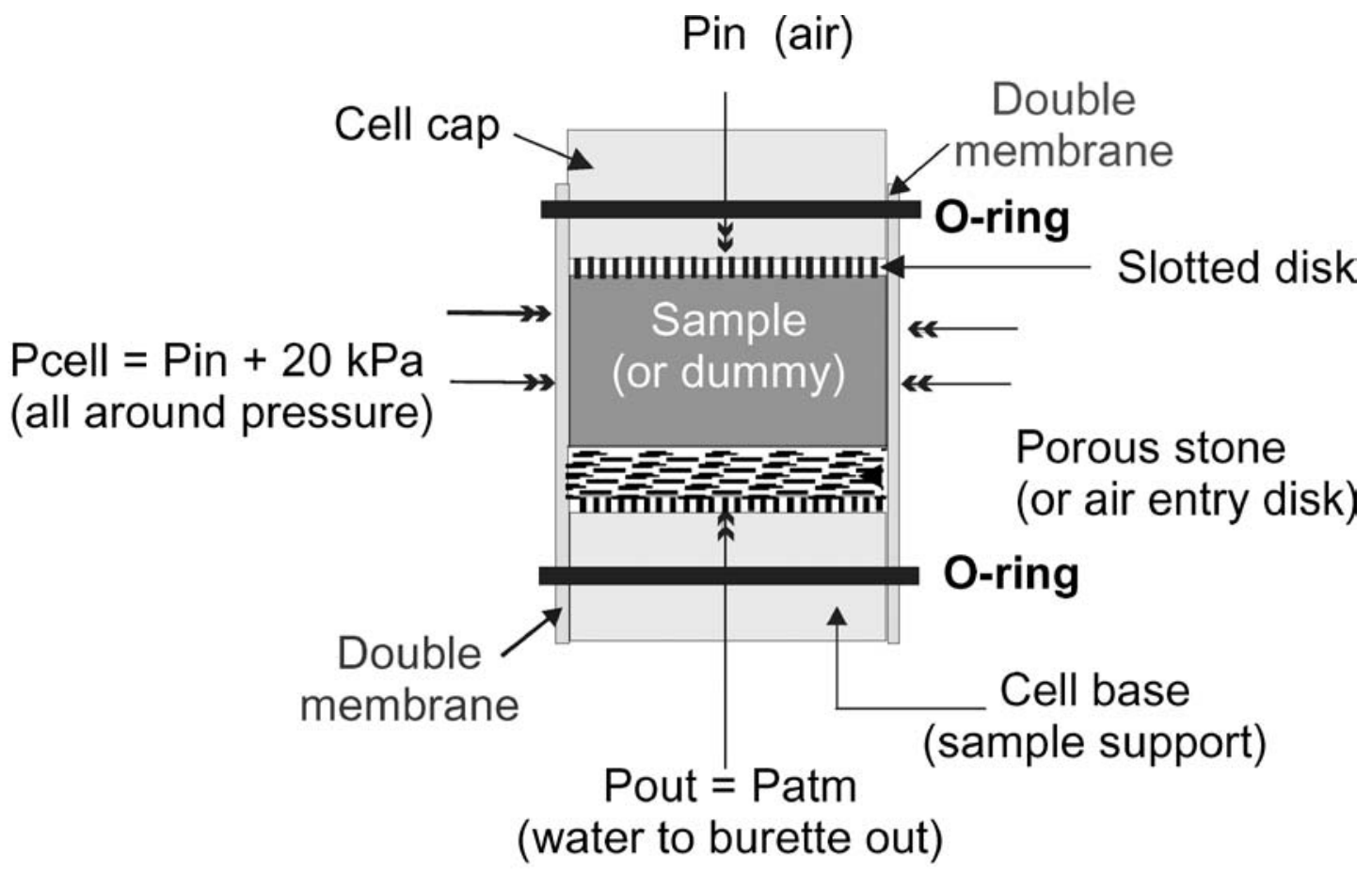

Note: The notation P stands for pressure

Not to scale

FIG. 3-Detail of cell and pressure application.

which is in turn placed inside a ceramic container to which vaccum is applied.

A series of tests were performed using porous stones with several AEVs (5-bar, 1-bar, and 0-bar). In the case of the study of deinking residues, the final choice of porous stone was mostly based on the time needed for equilibrium to be reached inside the burettes, after each pressure increment (procedure explained later). Consistent readings could not be made with the 5-bar porous stone before several weeks, whereas nearly a week was needed for equilibrium to be reached with the 1-bar porous stone. The porous stone with a negligible AEV (called here 0-bar porous stone) was thus retained for that part of the study. This was only possible because, in this setup, air is never applied directly on the porous stone.

Although the use of a 0-bar porous stone reduces the time needed for obtaining the AEV of the material, there is one limitation associated with its use: slightly beyond or at the AEV, bubbles start to appear in the burette OUT, indicating that the air applied at the top is breaking through the sample and reaching the porous stone at the bottom. As a consequence, the use of a 0-bar porous stone does not allow for obtaining the entire shape of the SWCC and, for that matter, the entire shape of the hydraulic conductivity function. If enough time is allowed for stabilization between readings, 1-bar (or 5-bar) porous stones can be used and the entire shape of the SWCC of compressible materials can be obtained. In the case of the present study, a few more points beyond the AEV were obtained. The procedure used for that step is explained later in the text (see Test Termination).

The surface perimeter of the porous stone was treated with a thin layer of resurfacing material (Epoxy in the present case) in order to prevent water or air from escaping from under the O-ring, where micro irregularities exist (they were indeed detected in the microscope).
The interior of the cell is filled with deaerated water and is connected to the burette CELL, which is under a pressure $P_{\text {cell }}$. Any change in volume of the sample during testing can be recorded from readings of the burette CELL. As a consequence, the exact volumetric water content and degree of saturation $(S)$ can be recorded for each air pressure level (equivalent to the suction level, since the axis-translation technique is applied).

For each pressure level, changes in volume of the various components of the testing apparatus, such as the Plexiglas cylinder and Tygon lines, must be subtracted from the recorded volume changes of the samples. This correction is obtained by means of a calibration of the system, whereby a test is run with all components assembled, except the sample. For calibration purposes, a flexible membrane covered the top cap, preventing air from actually coming out of it. The top cap was placed directly onto the base, so that the porous stone could "feel" the exerted pressure (which would not be possible if a solid dummy was placed). A flexible membrane covered the porous stone, top and bottom caps. Evaporation from the burette OUT was also recorded in order to correct the actual quantity of water flushed out of the system.

\section{Sample Preparation}

In the case of the study with DR, the first step of sample preparation was to treat the material to prevent biological activity from occurring during the tests. Gases produced due to degradation of organic matter could end up in the burette OUT, rendering monitoring of this burette more difficult and less accurate. After autoclaving the material, the microbiocide Busan 1030 was applied. The amount of microbiocide necessary was determined by Tremblay (2000).

Several preliminary tests with DR showed that the procedure that allowed for best reproducibility of results was to compact the 

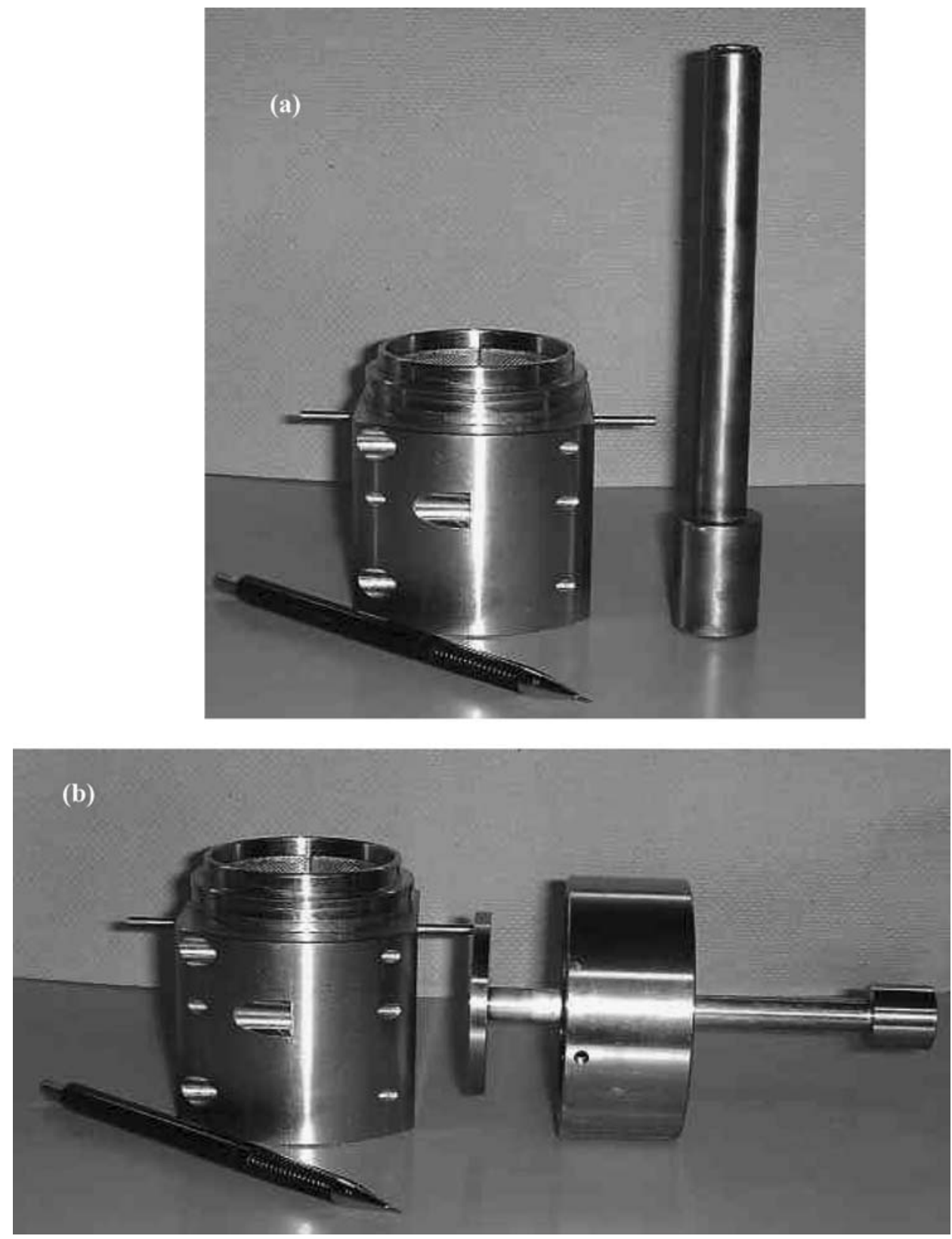

FIG. 4-Photograph of mold, mortar (a), and piston (b).

material by tamping in several layers of approximately $1 \mathrm{~cm}$ directly into the cell. For that purpose, a mold and a small mortar were designed and constructed to be used particularly with this testing apparatus (see detail in the photograph of Fig. 4a). It was found that compaction in several thin layers was not only easier, but allowed for the best level of homogeneity in terms of water content and density. The thickness of the layers could be verified by using the piston presented in the photograph of Fig. $4 b$.

Before placement of the first layer of the sample, the line OUT is filled with deaerated water and closed; the porous stone, previously saturated with deaerated water, is placed on the pedestal. The flexible membranes are then rapidly installed. By following this procedure, the sample cannot suck up water from the porous stone, since the latter is isolated from the exterior (no air can enter to replace any eventual displaced volume of water sucked up). No water is present on the slots of the top cap in the beginning of the test. Since air is applied from the top, it is not expected that any water would accumulate at that location.

The samples in the present study were compacted at gravimetric water contents in the vicinity of $140 \%$ to a dry unit weight $\left(\gamma_{d}\right)$ of approximately $5.0 \mathrm{kN} / \mathrm{m}^{3}$. Deinking residue samples at such densities and water contents attain a degree of saturation in the vicinity of 91-93\% (Burnotte et al. 2000). The goal in this investigation was to start the tests with the highest degree of saturation possible. By doing so, all SWCC start from nearly the same point. Backpressure was not applied to saturate the samples, since preliminary tests performed by Proulx (1997) showed that backpressure application rendered the determination of water entering and leaving the sample quite difficult with this apparatus. A poor determination resulted in erroneous evaluation of the volumetric water content and degree of saturation, which were determined at the end of the tests using the gravimetric water content and the sample dimensions. 
TABLE 2-General conditions of the deinking residue samples following consolidation.

\begin{tabular}{|c|c|c|c|c|c|c|c|c|}
\hline \multirow[b]{2}{*}{ Test } & \multirow[b]{2}{*}{$\begin{array}{c}\text { Compaction } \\
\text { Water Content }(\%)\end{array}$} & \multirow[b]{2}{*}{$\begin{array}{l}\text { Unit Weight } \\
\qquad\left(\mathrm{kN} / \mathrm{m}^{3}\right)\end{array}$} & \multirow[b]{2}{*}{$\mathrm{S}^{1}(\%)$} & \multicolumn{2}{|c|}{ Void Ratio } & \multirow[b]{2}{*}{$\theta^{2}(\%)$} & \multicolumn{2}{|c|}{ Vol of Sample $\left(\mathrm{cm}^{3}\right)$} \\
\hline & & & & $\begin{array}{c}\text { Before } \\
\text { Consolidation }\end{array}$ & $\begin{array}{c}\text { After } \\
\text { Consolidation }\end{array}$ & & $\begin{array}{c}\text { Before } \\
\text { Consolidation }\end{array}$ & $\begin{array}{c}\text { After } \\
\text { Consolidation }\end{array}$ \\
\hline 14 & 139.6 & 5.10 & 99.6 & 2.87 & 2.73 & 73.0 & 65.30 & 62.97 \\
\hline 15 & 144.1 & 4.92 & 99.4 & 3.01 & 2.75 & 72.9 & 66.35 & 62.07 \\
\hline 16 & 148.9 & 4.74 & 100.5 & 3.16 & 2.81 & 74.2 & 67.52 & 61.94 \\
\hline 17 & 140.8 & 4.71 & 98.0 & 3.19 & 2.80 & 72.2 & 65.12 & 59.09 \\
\hline$S-1^{3}$ & 197.8 & 3.86 & 94.2 & 4.11 & 3.64 & 73.9 & 66.73 & 60.68 \\
\hline
\end{tabular}

Note: Relative density $(\mathrm{Dr})=2.01$ according to several tests.

${ }^{1} \mathrm{~S}=$ Degree of saturation.

${ }^{2} \theta=$ Volumetric water content

3 The material for Test S-1 was taken from a degradation test that had been running for over a year.

\section{Testing}

Following compaction, the cell cap is mounted, and the O-rings installed (Figs. 2 and 3) in order to proceed with the consolidation phase. Consolidation takes place once the cell is under a confining pressure of $20 \mathrm{kPa}$ ( $2 \mathrm{~m}$ of water column) plus $2 \mathrm{kPa}$ of air pressure applied from the top. At that point, $\mathrm{P}_{\text {air }}=2 \mathrm{kPa}$ and $\mathrm{P}_{\text {cell }}=22 \mathrm{kPa}$ (or $2+20 \mathrm{kPa}$ ). The sample is thus consolidated at $22 \mathrm{kPa}$. Planchet (2001) provides the detailed procedure of sample preparation, compaction, and consolidation for the case of deinking residues.

In one case, a degree of saturation slightly over $100 \%$ was obtained. This was attributed to imperfect readings and/or limitations in the calculation of the initial parameters. The conditions of all samples just after consolidation are summarized in Table 2 .

The first point of the SWCC $\left(P_{\text {air }} ; S\right.$ or $\left.\theta\right)$ is taken at the end of the consolidation under $22 \mathrm{kPa}$, which occurs when the water levels in the burettes CELL and OUT reach equilibrium. At this point, readings are initialized and the air pressure, $P_{\text {in }}$, is increased by $\Delta P$ in order to obtain other points of the curve. Several tests with deinking residues showed that a good repeatability of results was achieved with $\Delta P=2.5 \mathrm{kPa}$ and time steps $(\Delta t)$ of $24 \mathrm{~h}$. For other materials, or when using different porous stones, other time steps and pressure increments must be determined.

During each time step, the amounts of water entering the cell (from burette CELL) and reaching the burette OUT are recorded. The first corresponds to the changes in volume of the sample, whereas the second indicates how much water was lost from the samples. After the appropriate corrections (obtained from the calibration procedure) are applied to these two measurements, it is possible to calculate the water content and degree of saturation of the sample. Since the axis-translation technique is applied, the associated suction is that applied to the top of the sample (i.e., $P_{\text {air }}$ ).

\section{Test Termination and Cell Disassembling}

Normally, a test to determine the SWCC ends when one of the following happens:

1. The applied air pressure becomes greater than the AEV of the porous stone (this implies that a porous stone with an AEV greater than that of the sample is being used). At this point, air bubbles reach the burette OUT, rendering further monitoring of water content practically impossible or highly inaccurate.

2. The maximum pressure of the air pressure regulator is achieved.
In the latter case, if the water contents at higher suction levels are required for the purpose of a particular study, either a different pressure regulator or test setup may be the solution (see Table 1).

In the case of DR, the tests were not terminated immediately after bubbles appeared in the burette OUT. Right after the AEV was reached, the following procedure was adopted in order to obtain a few more points of the SWCC:

1. Record the reading of the burette CELL (necessary to calculate volume changes-not affected by bubbles),

2. Lower the air pressure to a level below the AEV value,

3. Read the water level of the burette OUT (necessary to calculate the volumetric water content and degree of saturation),

4. Apply a new air pressure level for further readings.

As discussed in the Results, this procedural adaptation does not ensure that the points obtained beyond the AEV represent the actual residual volumetric water contents (and degree of saturation) for the applied suction.

Beyond a certain level of air pressure application, it becomes practically impossible to observe any change in $S$ or $\theta$, given the presence of preferential paths inside the sample. The test is then terminated, the cell disassembled, and the dimensions and weight of the sample are taken. If, for the purpose of a particular study, it is necessary to obtain the remaining part of the SWCC, 1-bar (or 5bar) AEV porous stones may be used. As explained above, with the use of 1-bar or 5-bar porous stones the time needed for equilibrium to be reached increases significantly.

\section{Results}

Figure 5 presents the SWCC of four tests performed following the procedure described previously. The SWCC is represented in two ways: Fig. $5 a$ shows the relationship between degree of saturation and suction, whereas Fig. $5 b$ presents the relationship between volumetric water content and suction. While the characteristic curves follow a similar pattern, the AEV varies between 15 and $25 \mathrm{kPa}$.

The AEV represents the suction at which the largest pores will desaturate. The smaller pores remain saturated and eventually desaturate at higher suction levels. The scatter in Fig. 5 may thus be attributed to differences in the pore distribution of each sample. Indeed, the structure of compacted DR is quite variable, with several macro pores present between crumbs (or aggregates), inside which micro pores are found (Cabral et al. 1999; Panarotto et al. 1999; Panarotto 2001). In addition, the initial void ratio is directly affected by the cell pressure. As demostrated by Vanapalli et al. (1999), a 
SWCC - Deinking Residues

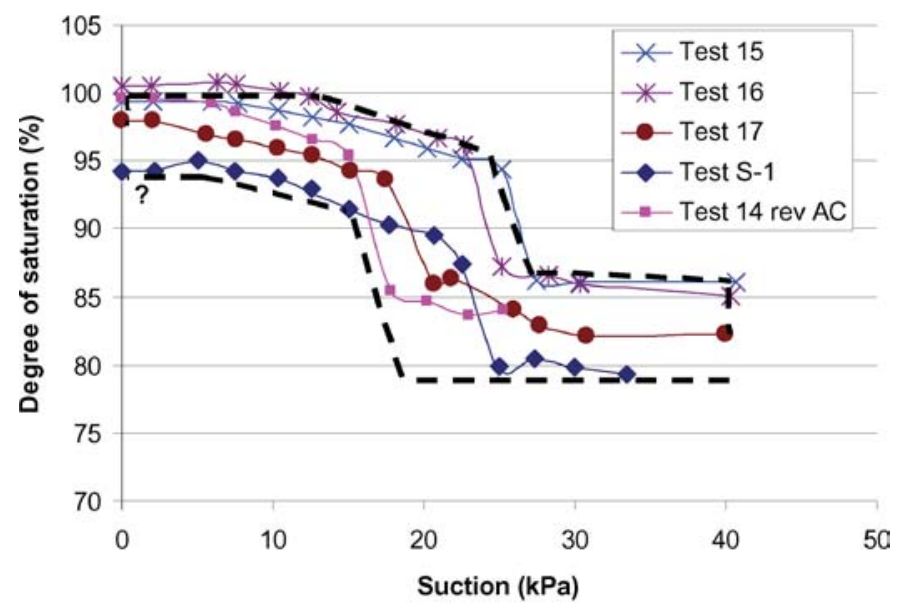

(a)

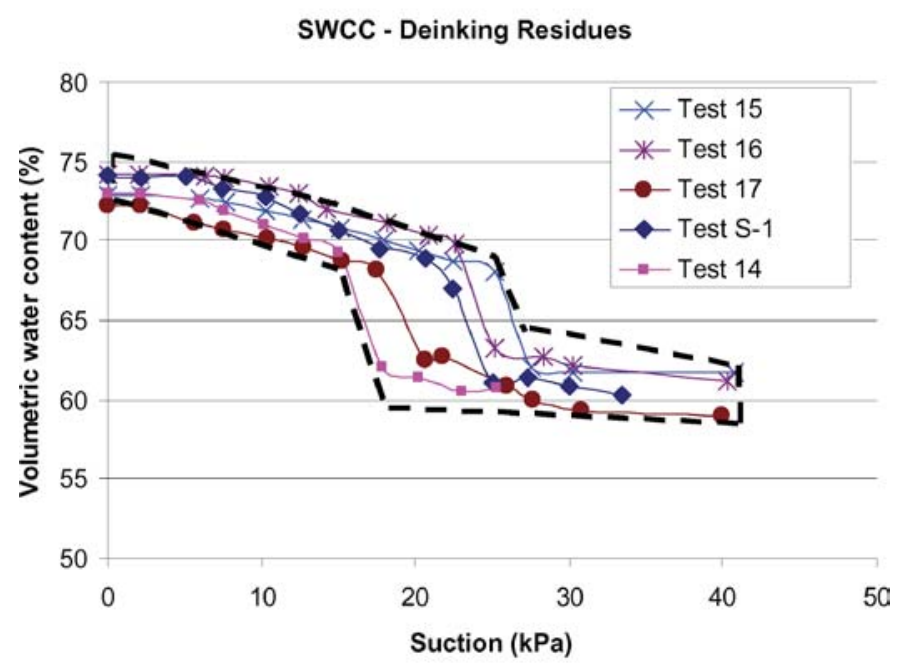

(b)

FIG. 5-SWCC of Deinking Residues.

reduction in void ratio causes an increase in AEV. At suction levels higher than the AEV, the slope of the SWCC of compressible soils is slightly affected by the initial void ratio, thus by the cell pressure.

In the case of the results presented in Fig. 5, the almost constant (and rather high) values of $S$ or $\theta$ observed for air pressures higher than the AEV do not represent the residual water contents as usually defined. In fact, the air breakthrough that occurs following the AEV eventually prevents further desaturation of the samples. As a consequence, the observation of the air breakthrough is a helpful hint that the AEV has been achieved; but if the purpose of the test is to define the complete SWCC, a porous stone with an appropriate AEV should be used, as noted previously.

It can be seen in Fig. 6 that the volumetric water content and degree of saturation may be significantly underestimated if the variation in volume of the sample is not properly considered when obtaining the SWCC for compressible materials. One important consequence is that hydraulic conductivity $(k)$ functions obtained by mathematical models based on the SWCC will lead to lower values than when the correction is made.

It is also worth noting that it is a characteristic of the axis translation technique to prevent cavitation within the sample (e.g., Hilf
1956). A big void initially saturated and isolated in the middle of the sample will not be emptied until one of the surrounding pores desaturates. In the field, desaturation may occur immediately since cavitation is not prevented.

\section{Final Comments}

Some materials, like deinking residues, are compacted in the field at relatively high water content in order to minimize its hydraulic conductivity (Cabral et al. 1999; Burnotte et al. 2000). The compacted material remains fairly compressible even under low stresses (Burnotte et al. 2000; Robart 1998). The compressibility of such materials makes it difficult to determine the water retention curve by standard procedures. For example, if a suction of $20 \mathrm{kPa}$ is applied to a sample of deinking residue, the resulting increase in effective stress is high enough to cause some drainage, which, however, does not imply desaturation, but simply reflects a change of volume or consolidation.

This paper presented the investigation of a test procedure to monitor the change of volume in addition to the volume of water expelled from the specimen during each step of air pressure increase (i.e.,

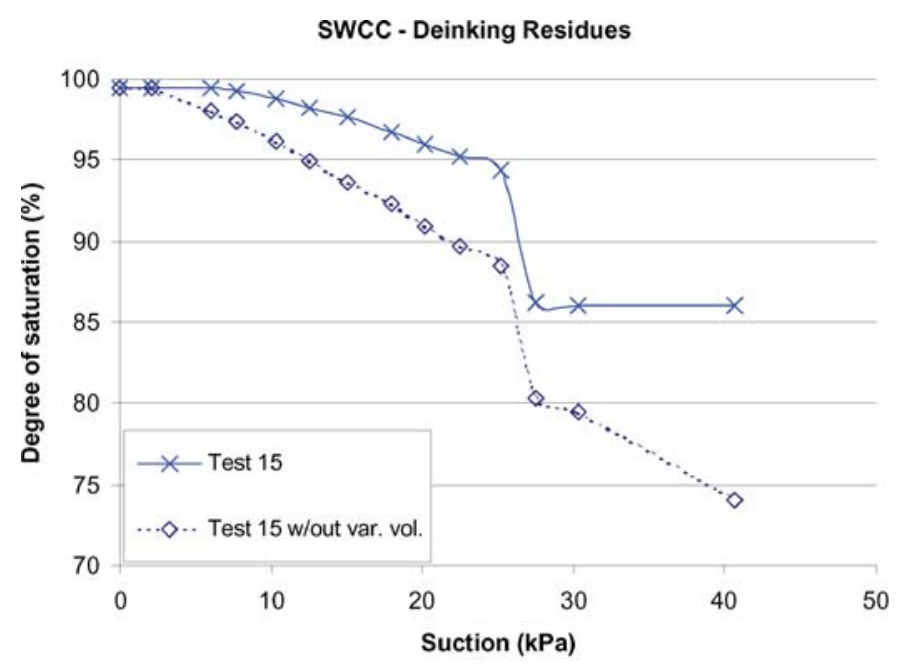

(a)

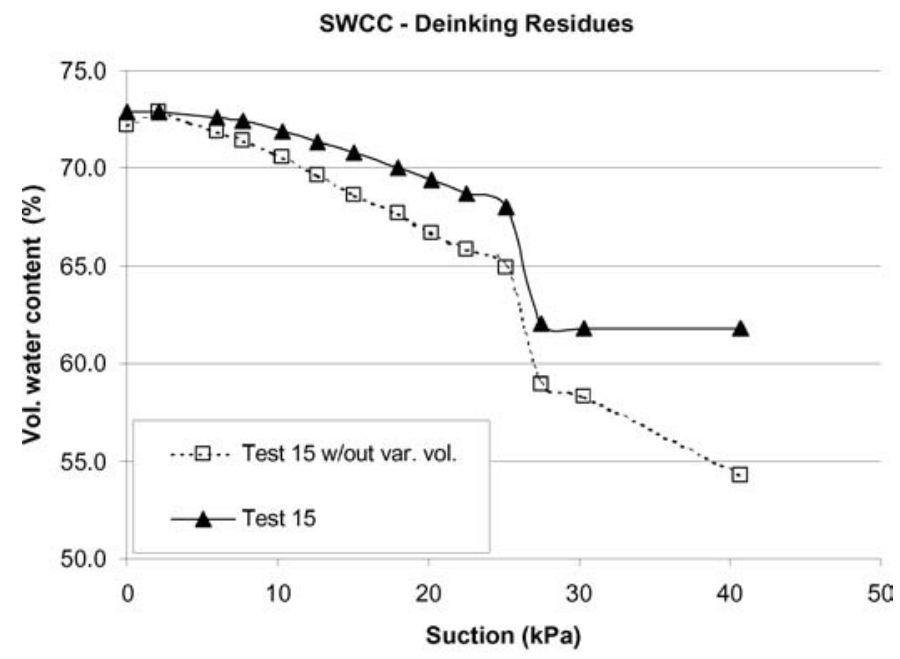

(b)

FIG. 6-SWCC of deinking residues with and without consideration of the variation of volume of the sample. 
suction increase, since the axis translation technique is employed). This allows the proper calculation of the degree of saturation during the tests, even if the material being tested is highly compressible. In standard pressure plate tests (Fredlund and Rahardjo 1993), the effective stress in the specimen, at equilibrium, becomes equal to the air pressure applied on the specimen. In the test setup described in this paper, the cell pressure is maintained at a value of $20 \mathrm{kPa}$ higher than the air pressure applied at the top of the specimen in order to minimize the risk of the air escaping between the confining membrane and the specimens. At equilibrium, the effective stress in the specimen is thus $20 \mathrm{kPa}$ higher than air pressure applied at the top of the specimen.

In pressure plate tests, each step of air pressure increase generally lasts several days, due to the low hydraulic conductivity of the porous stone. Since the air pressure is not applied directly on the porous stone but only on the specimen, the setup described in this paper allows, if desired, the performance of a test with a coarse porous stone in order to have a shorter duration test, or a test with more steps. When the air pressure is sufficiently high to break through the specimen, the air migrates through the coarse porous stone. The observation of air bubbling in the burette OUT confirms that the specimen AEV has been exceeded, but on the other hand, makes it impossible to continue the determination of the water retention curve, due to the formation of a preferential air path. An appropriate low AEV porous stone should be used if the complete determination of the water retention curve is desired.

\section{Acknowledgments}

This research was partly supported by a University-Industry partnership grant 192179 from the National Science and Engineering Research Council of Canada (NSERC) and Industries Cascades and Les Papiers Perkins. The help from Serge-Étienne Parent, Research Assistant, with some of the tests is also acknowledged.

\section{References}

Aubertin, M., Bussière, B., Barbera, J.-M., Chapuis, R. P., Monzon, M., and Aachib, M., 1997, "Construction and Instrumentation of In Situ Test Plots to Evaluate Covers Built with Clean Tailings," Proceedings of the 4th ICARD, Vancouver, B.C., Vol. 2, pp. 715730.

Barbour, S. L., 1990, "Reduction of Acid Generation in Mine Tailings Through the Use of Moisture-Retaining Cover Layers as Oxygen Barriers: Discussion," Canadian Geotechnical Journal, Vol. 27, pp. 398-401.

Barbour, S. L., 1998, “The Soil-Water Characteristic Curve: A Historical Perspective (Nineteenth Canadian Geotechnical Colloquium)," Canadian Geotechnical Journal, Vol. 35, pp. 873-894.

Black, W. P. M. and Corey, A. T., 1957, "Pore Water Pressure and Moisture Content Studies under Experimental Pavements," Proceeding of the 4th International Conference on Soil Mechanics Foundation Engineering, London, UK, 12-24 August, Vol. 2, pp. 94-103.

Brooks, R. H. and Corey, A. T., 1964, "Hydraulic Properties of Porous Media," Hydrology Paper 27, No. 3, Colorado State University., Fort Collins, CO.

Brown, R. A., Fourie, A. B., and Snyman, R., 1998, "Pulp Sludge: Waste or Valuable Capping Material?" Proceedings of Wastecon '98, 14th Congress of the Institute of Waste Management, Kempton Park, South Africa, October, pp. 564-579.
Burnotte, F., Lefebvre, G., Cabral, A. R., Audet, C., and Veilleux, A., 2000, "Use of Deinking Residues for the Final Cover of a MSW Landfill," Proceedings of the 53rd Canadian Geotechnical Conference, Montreal, Quebec, October, Vol. 1, pp. 585-591.

Cabral, A. R., Burnotte, F., Lefebvre, G., Amyot, G., and Lacasse, G., 1999, "Design Construction and Monitoring of a Waste Rock Cover Using Pulp and Paper Residues," Proceedings of the Symposium on Tailings and Mine Wastes '99, Fort Collins, CO, January.

Cabral, A. R., Racine, I., Burnotte, F., and Lefebvre, G., 2000, "Diffusion of Oxygen through a Pulp and Paper Residue Barrier," Canadian Geotechnical Journal, Vol. 37, pp. 201-217.

Croney, D., 1952, "The Movement and Distribution of Water in Soils," Géotechnique, Vol. 3, pp. 1-16.

Croney, D. and Coleman, J. D., 1954, "Soil Structure in Relation to Soil Suction (pF)," Journal of Soil Sciences, Vol. 5, No. 1, pp. 75-84.

Fawcett, R. G. and Collis-George, N., 1967, “A Filter-Paper Method for Determining the Moisture Characteristics of Soil," Australian Journal of Experimental Agriculture and Animal Husbandry, Vol. 7, pp. 162-167.

Fredlund, D. G. and Rahardjo, H., 1993, Soil Mechanics for Unsaturated Soils, Wiley-Intersciences Publication, New York.

Fredlund, M. D., Wilson, G. W., and Fredlund, D. G., 1997, "Prediction of the Soil-Water Characteristic Curve from the Grain Size Distribution Curve," Proceedings of the 3rd Brazilian Symposium on Unsaturated Soils, Rio de Janeiro, Brazil, 20-22 April, pp. 13-23.

Hilf, J. W., 1956, “An Investigation of Pore-Water Pressures in Compacted Cohesive Soils," Ph.D. thesis, University of Colorado, Denver.

Kraus, J. F., Benson, C. H., Van Maltby, C., and Wang, X., 1997, "Laboratory and Field Hydraulic Conductivity of Three Compacted Paper Mill Sludges," American Society of Civil Engineers, Journal of Geotechnical and Geoenvironmental Engineering, Vol. 123, No. 7, pp. 654-662.

Marinho, F. A. M., 1994, "Shrinkage Behaviour of Some Plastic Soils," Ph.D. Thesis, Department of Civil Engineering, Imperial College of Science, Technology and Medicine, London, England. Moo-Young, H. K. and Zimmie, T. F., 1996, "Effects of Organic Decomposition on Paper Mill Sludges Used as Landfill Cover Material," Proceedings of the 2nd International Conference on Environmental Geotechnics, Osaka, Japan, M. Kamon, Ed., November. Balkema.

Nicholson, R. V., Gillham, R. W., Cherry, J. A., and Reardon, E. J., 1989, "Reduction of Acid Generation in Mine Tailings Through the Use of Moisture-Retaining Cover Layers as Oxygen Barriers," Canadian Geotechnical Journal, Vol. 26, pp. 1-8.

Panarotto*, C. T., 2001, "Évolution Biochimique des Résidus de Désencrage dans un Contexte de Valorisation Comme Barrière de Recouvrement," Ph.D. Thesis, Department of Civil Engineering, Université de Sherbrooke, Canada. February 2001.

(*Actual reference to thesis under Maiden name: Teixeira, C.E.).

Panarotto, C. T., Robart, G., Cabral, A., Chartier, R., Burnotte, F., and Lefebvre, G., 1999, "Using Deinking Residues in Cover Systems," Proceedings, 7th Waste Management and Landfill Symposium (Sardinia '99), Christensen, Cossu, and Stegmann, Eds., S. Margherita di Pula_Cagliari, Sardinia, Italy, 1999. Vol. III, pp. 357-364.

Planchet, L., 2001, “Utilisation des Résidus de Désencrage Comme Barrière Capillaire ou Evapo-Transpirative (ET) pour des Parcs à Résidus Miniers Producteurs de DMA," Masters Thesis, 
Department of Civil Engineering, Université de Sherbrooke, Quebec, Canada.

Proulx, M.-F., 1997, “La Capacité de Rétention d'eau des Résidus de Désencrage Utilisés Comme Matériau de Recouvrement des Sites Miniers Producteurs de DMA," Master's Thesis, Department of Civil Engineering, Université de Sherbrooke, Quebec, Canada.

Richards, L. A. and Fireman, M., 1943, "Pressure-Plate Apparatus for Measuring Moisture Sorption and Transmission by Soils," Soil Sciences, Vol. 56, pp. 395-404.

Robart, G., 1998, "Étude de la Perméabilité et de la Compressibilité des Résidus de Désencrage," Masters Thesis, Department of Civil Engineering, Université de Sherbrooke, Canada, February.

Tremblay, P., 2000, "Étude de la Migration d' Oxygène à l' intérieur d'une Membrane Constituée de Résidus de Désencrage, Masters Thesis, Department of Civil Engineering, Université de Sherbrooke, Canada, April.

Vanapalli, S. K., Fredlund, D. G., and Pufahl, D. E., 1999, “The Influence of Soil Structure and Stress History on the Soil-Water Characteristics of a Compacted Till," Géotechnique, Vol. 49, No. 2, pp. 143-159.
Woyshner, M. R. and Yanful, E. K., 1995, "Modelling and Field Measurements of Water Percolation Through an Experimental Soil Cover on Mine Tailings," Canadian Geotechnical Journal, Vol. 32, No. 4, pp. 601-609.

Yanful, E. K., Bell, A. V., and Woyshner, M. R., 1993a, "Design of a Composite Soil Cover for an Experimental Waste Rock Pile near Newcastle, New Brunswick, Canada," Canadian Geotechnical Journal, Vol. 30, No. 4, pp. 578-587.

Yanful, E. K., Riley, M. D., Woyshner, M. R., and Duncan, J., 1993b, "Construction and Monitoring of a Composite Soil Cover on an Experimental Waste-Rock Pile near Newcastle, New Brunswick, Canada," Canadian Geotechnical Journal, Vol. 30, No. 4, pp. 588-599.

Yanful, E. K., 1993, "Oxygen Diffusion through Soil Covers on Sulphidic Mine Tailings," American Society of Civil Engineers, Journal of Geotechnical Engineering, Vol. 119, pp. 12071228.

Verbrugge, J., 1976, "Contribution to Measuring Suction and Interstitial Pressure in Unsaturated Soils," U.S. Army Cold Regions Research and Engineering Laboratory, pp. 9-28 in CRREL Report No: TL 529, Hanover, NH. 